\title{
MATERNAL AND PERINATAL OUTCOME IN POSTDATED PREGNANCY: A STUDY OF 100 CASES IN BANGLADESH ARMED FORCES
}

\author{
Akhter S
}

\begin{abstract}
Introduction: Any pregnancy which has passed beyond the Expected Date of Delivery (EDD) is called postdated pregnancy or prolonged pregnancy. But when pregnancy has prolonged beyond 42 weeks are called postmaturity or post term pregnancy. Incidence of prolonged pregnancy is $3-14 \%$ of all gestations.
\end{abstract}

Aim: The aim of the study is to determine the foetal and maternal outcome and complications in patients presenting with postdated pregnancy in Combined Military Hospital of Bangladesh Armed Forces.

Materials \& Methods: A cross-sectional study was conducted for one year at the Department of Gynecology and Obstetrics in Combined Military Hospital, Dhaka. During this period total 100 cases were studied. Cases were selected randomly. Here postdatism was applied to any pregnancy which exceeded the EDD and it also included postmaturity which is pregnancy extending beyond 42 completed weeks. A preformed proforma was used to collect data which were analyzed later on.

Results: Amongst 1853 cases of labour patients, 273 cases were postdated pregnancy and 169 cases postmaturity. The incidence of postdated pregnancy in this series was $15 \%$ and postmaturity was $9.14 \%$. 93\% patients had regular antenatal checkup. $82 \%$ patients were presented not in labour situation. $60 \%$ cases were NVD and $40 \%$ cases LUCS was done. No craniotomy or forceps was required. There was no maternal death. But there were two Intra Uterine Deaths (IUD) and one neonatal death due to umbilical sepsis.
Conclusion: Any pregnancy that goes beyond 41 weeks of confirmed gestational age foetal well-being must be assessed. Proper management is a pre-requisite to reduce the rate of perinatal mortality and morbidity in this group of patient.

Key-words: Postdated Pregnancy, Perinatal Outcome, Maternal Outcome, Prolonged Pregnancy.

\section{Introduction}

Any pregnancy which has passed beyond EDD is called postdated pregnancy or prolonged pregnancy. But when pregnancy has prolonged beyond 42 weeks are called postmaturity or post term pregnancy ${ }^{1}$. Incidence of prolonged pregnancy is $3-14 \%$ of all gestations ${ }^{2}$. It is still obscure why some women go into premature labour while others have prolonged pregnancy. Certain factors are related to postdated pregnancy, these are hereditary factor, high standard of living, sedentary habits, anencephaly, elderly primigravidae, elderly multigravidae etc. Previous history of postterm pregnancy has $50 \%$ risk of recurrence ${ }^{3}$. When any pregnancy advances beyond the EDC (Expected Date of Confinement) perinatal mortality and foetal morbidity also increases. Based on national birthday Trust Data from Britain in 1958, the perinatal mortality rate increases after 42 weeks gestation, doubles at 43 weeks and quadruples at 44 weeks gestation ${ }^{2,4,5}$. These postterm infants have higher rate of mortality up to two years of $\mathrm{age}^{2}$. So interference of pregnancy is done beyond 41 weeks provided the maturity of foetus is ascertained by

Lt Col Salina Akhter, MBBS, DGO, FCPS (Gyne and Obs), Classified Specialist in Gyne and Obs, Combined Military Hospital, Comilla Cantonment. 
history, clinical examination and ancillary aids. Common mode of interference is induction of labour because some pregnancies failed to go into spontaneous labour due to failure of responsiveness to oxytocin or deficiency of placental sulphatase enzyme or diminished secretion of oxytocin as in anencephalic babies.

Postmaturity syndrome (Foetal dysmaturity) associated with $5 \%-10 \%$ of prolonged pregnancy. These foetuses have decreased amount of subcutaneous fat and wrinkled skin (because they have lost the vernix caseosa), long hair and long finger nails. Prolonged pregnancy complications ideally should be discovered before labour because these foetuses are fragile, tolerate labour poorly and frequently are acidotic at birth. These groups of babies have higher rate of perinatal mortality ${ }^{1}$. About $1 / 3$ rd death occur antepartum, $1 / 2$ intrapartum and about $1 / 6$ th neonatal ${ }^{4}$. Any pregnancy that goes beyond 41 weeks of confirmed gestational age foetal well-being must be assessed. Proper management is a prerequisite to reduce the rate of perinatal mortality and morbidity in this group of patient ${ }^{2}$.

\section{Materials and Methods}

This cross-sectional study was conducted in the Department of Obstetrics and Gynecology in Combined Military Hospital, Dhaka for a year. Cases were selected randomly. Here postdatism was applied to any pregnancy which exceeded the EDD and it also included postmaturity which is pregnancy extending beyond 42 completed weeks. A preformed proforma was used to collect data regarding age, parity, antenatal checkup, gestational age at the time of reporting. Patients having regular menstrual cycle were sure about their LMP and those were having adequate liquor and cephalic presentation was included in this study. Patient having irregular cycle, having medical disorder (Heart Disease, Diabetes Mellitus, Renal Disease etc) and obstetric complications (Multiple Pregnancy, Congenital Anomalies, Abnormal Presentation, Pre Eclamtic Toxaemia (PET), Eclampsia) were excluded. In this study, determination of gestational age were done by LMP, fundal height measurement, Ultra Sono Graphy (USG) report, clinical assessment before delivery and baby examination after birth. Patients who came in labour, close monitoring of maternal and foetal condition were done by using partograph and Cardio Toco Graphy (CTG). Patients who were not in labour but completed 41 weeks of pregnancy were managed by sweeping or by induction either with intra-cervical Foley's catheter or by oxytocin drip or both. But patients who did not cross 41 weeks of gestation were waited for spontaneous onset of labour up to 41 completed weeks.

\section{Results}

Among 1853 pregnancy cases, 273 were postdated and 169 were postmaturity cases. The incidence of postdated pregnancy in this study was $15 \%$ and postmaturity was $9.14 \%$. Postdated pregnancy was more common in young age group than in elderly patients.

Table-I showed, $60 \%$ cases of postdated pregnancy were between 20-29 years of age. Only $10 \%$ was at or above 30 years of age.

Table-I: Age Incidence ( $\mathrm{n}=100)$.

\begin{tabular}{|l|c|c|}
\hline Age Groups & No of Cases & Percentage \\
\hline Below 29 years & 30 & $30 \%$ \\
\hline $20-29$ years & 60 & $60 \%$ \\
\hline 30 years onwards & 10 & $10 \%$ \\
\hline
\end{tabular}

Postdated pregnancy is more common in multigravida (Table-II).

Table-II: Parity of the Patients ( $n=100)$.

\begin{tabular}{|l|c|c|}
\hline Gravida & No of Cases & Percentage \\
\hline Primigravida & 47 & $47 \%$ \\
\hline Multigravida & 53 & $53 \%$ \\
\hline
\end{tabular}

Table-III showed $91 \%$ patient presented at $40.1-42$ weeks, $8 \%$ patients at $42.1-43$ weeks and only $1 \%$ patients presented at 43.1 weeks onwards in $\mathrm{CMH}$ Dhaka.

Table-III: Duration of Pregnancy $(n=100)$.

\begin{tabular}{|l|c|c|}
\hline Duration of Pregnancy & No of Cases & Percentage \\
\hline $40.1-42$ Weeks & 91 & $91 \%$ \\
\hline $42.1-43$ Weeks & 8 & $8 \%$ \\
\hline $43.1-$ Onwards & 1 & $1 \%$ \\
\hline
\end{tabular}


Most of the $(93 \%)$ patients had regular antenatal checkup (Table-IV).

Table-IV: Antenatal Checkup (ANC) $(n=100)$.

\begin{tabular}{|l|c|c|}
\hline ANC & No of Cases & Percentage \\
\hline Regular Checkup & 93 & $93 \%$ \\
\hline Irregular Checkup & 4 & $4 \%$ \\
\hline No Checkup & 3 & $3 \%$ \\
\hline
\end{tabular}

Biparietall Diameter (BPD) and femoral length together can give an idea about maturity, not postmaturity in late pregnancy. But along with other clinical parameter it helps in diagnosis of postmaturity (Table-V).

Table-V: BPD and Femoral Length in USG Report $(n=100)$.

\begin{tabular}{|l|c|c|c|}
\hline BPD & Femoral Length & No of Cases & Percentage \\
\hline $96-98 \mathrm{~mm}$ & $67-76 \mathrm{~mm}$ & 8 & $8 \%$ \\
\hline $92-95 \mathrm{~mm}$ & $67-76 \mathrm{~mm}$ & 76 & $76 \%$ \\
\hline $90-95 \mathrm{~mm}$ & $66-72 \mathrm{~mm}$ & 13 & $13 \%$ \\
\hline $89-90 \mathrm{~mm}$ & $68 \mathrm{~mm}$ & 3 & $3 \%$ \\
\hline
\end{tabular}

Table-VI showed $78 \%$ patients had adequate liquor volume. Clinical assessment about amniotic fluid and USG reports coincided in this study.

Table-VI: Amniotic Fluid Volume in USG Reports ( $n=100)$.

\begin{tabular}{|l|c|c|}
\hline Amount of Liquor amnii & No of Patient & Percentage \\
\hline Adequate & 78 & $78 \%$ \\
\hline Inadequate & 18 & $18 \%$ \\
\hline Scanty & 4 & $4 \%$ \\
\hline
\end{tabular}

In this study group, $60 \%$ patient delivered vaginally. No craniotomy or forceps was done (Table-VII).

Table-VII: Mode of Delivery $(n=100)$.

\begin{tabular}{|l|l|l|c|c|}
\hline S/No & \multicolumn{2}{|l|}{ Type of Delivery } & No of Cases & Percentage \\
\hline 1. & Vaginal Delivery & Induced & 30 & $30 \%$ \\
\cline { 3 - 5 } & & Spontaneous & 21 & $21 \%$ \\
\hline 2. & Forceps & - & - \\
\hline 3. & Ventose & 09 & $9 \%$ \\
\hline 4. & Craniotomy & - & - \\
\hline 5. & \multicolumn{2}{|l|}{ Caesarean Section } & 40 & $40 \%$ \\
\hline
\end{tabular}

In this series of 100 cases, perinatal mortality was 3\%, among these two were Intra Uterine Foetal Death (IUFD) and one neonatal death was due to umbilical sepsis (Table-VIII).

Table-VIII: Perinatal Mortality.

\begin{tabular}{|l|c|c|c|c|}
\hline Items & Spontaneous & Caesarean & Ventose & Total \\
\hline Intrauterine Death & 2 & 0 & 0 & 2 \\
\hline Neonatal Death & 0 & 0 & 1 & 1 \\
\hline Total & 2 & 0 & 1 & 3 \\
\hline
\end{tabular}

Amongst the delivered babies, $86 \%$ babies had APGAR score 7-10 which was due to active interference in time during labour (Table-IX).

Table-IX: APGAR Score of Foetus 5 Minutes after Delivery ( $\mathrm{N}=98$ ).

\begin{tabular}{|l|c|c|c|}
\hline Types of Labour & $\begin{array}{c}\text { APGAR Score } \\
7-10\end{array}$ & $\begin{array}{c}\text { APGAR Score } \\
4-7\end{array}$ & $\begin{array}{c}\text { Apgar score } \\
\leq 4\end{array}$ \\
\hline Spontaneous Labour & 4 & 5 & - \\
\hline Induced Labour & 44 & 4 & 1 \\
\hline LUCS & 38 & 2 & 0 \\
\hline
\end{tabular}

There was no maternal death in the series. Morbidity in the form of PPH and UTI occurred in $5 \%$ only. There was no puerperal sepsis or wound infection (Table-X).

Table-X: Maternal Morbidity.

\begin{tabular}{|l|c|c|}
\hline Type of Morbidity & No of Cases & Percentage \\
\hline Post-Partum Haemorrhage & 4 & $4 \%$ \\
\hline Urinary Tract Infection & 1 & $1 \%$ \\
\hline Puerperal Sepsis & Nil & $0 \%$ \\
\hline Wound Infection & Nil & $0 \%$ \\
\hline
\end{tabular}

Table-XI shows foetal morbidity in the form of physiological jaundice which is $23 \%$.

Table-XI: Neonatal Morbidity.

\begin{tabular}{|l|c|c|}
\hline Type of Morbidity & Number of Cases & Percentage \\
\hline Physiological Jaundice & 23 & $23 \%$ \\
\hline Umbilical Sepsis & 2 & $2 \%$ \\
\hline Respiratory Tract Infections & 4 & $4 \%$ \\
\hline Septicaemia & 1 & $1 \%$ \\
\hline
\end{tabular}

\section{Discussion}

Post-term or postdated pregnancy is a high risk obstetrics situation. The perinatal mortality and morbidity are increased in several folds when pregnancy advanced beyond term i.e. 40 weeks. During this study period a total of 1853 patients were admitted in $\mathrm{CMH}$, Dhaka in antenatal and labour ward. Among these 169 patients exceeded EDD by 14 days (that is postmaturity) which constitute $9.14 \%$ and postdated pregnancy were $273(15 \%)$. Previous studies showed incidences were $3-14 \%$ and $11 \%$ respectively ${ }^{1,2}$. Prolongation of pregnancy beyond 40 weeks occurs much more frequently than postmaturity ${ }^{1}$. It was noted $10-15 \%$ beyond 41-42 weeks $^{6,7}$. So the incidence is within the standard limit. 
Incidence of postdated pregnancy in teen age group was $30 \%$, which in higher age group (30 years and above) was $10 \%$. Postdated pregnancy was more prevalent in 20-29 years of age group. In our country, $80 \%$ of the women by the age of 18 years become mother of at least one child. So, that may be the the cause of higher incidence in lower age group and in multigravida. In this study group, prevalence of postdated pregnancy is more in multigravida. This study had shown prevalence $53 \%$ in multigravida and $47 \%$ in primi. One study in the Bangabandhu Sheikh Mujib Medical University Hospital (BSMMUH) enumerates opposite epidemiology ${ }^{4}$. But study on same subject at Sylhet MAG Osmani Medical College Hospital has coincided with this study ${ }^{5}$. So, it needs further evaluation.

In this study, $91 \%$ patient presented at $40.1-42$ weeks, $8 \%$ at $42-43$ weeks, $1 \%$ at 43 weeks of pregnancy. This difference might be due to lack of education, ignorance and unawareness about the complication of post maturity which could be overcome by proper antenatal care and health education. Exact aetiology of prolonged pregnancy is not known. One established cause is congenital anomaly e.g. anencephaly foetus. These babies failed to secrete oxytocin from pituitary and cortisol from adrenal gland which are thought to be essential for initiation of labour ${ }^{8}$. But no such baby was found in this study group. Diagnosis was made on the basis of history and clinical examination. There were facilities for USG. Though diagnosis of maturity was possible by USG but post maturity could not be diagnosed unless early dating USG was supplied.

To see the foetal maturity early USG can be relied on. Ninety six percent of patient had regular antenatal checkup and supplied with early USG. Liquor volume was assessed clinically and by USG. Seventy eight percent patients have adequate liquor both clinically and ultrasonography. Twenty two percent patients had decreased liquor volume. This postterm foetuses appear to be associated with impaired foetal cardiac function with reduced amniotic fluid leads to chronic hypoxia and presence of meconium in liquor ${ }^{1,9}$.
By USG and clinically foetal macrosomia was present in three cases which contribute $3 \%$ of incidence of macrosomia in prolonged pregnancy. Previous studies have shown about $14 \%$ and $25.7 \%$ respectively ${ }^{8,9}$. In this study $39 \%$ patients started labour pain either in hospital or at home. Hospital policy in $\mathrm{CMH}$ Dhaka was routinely wait for spontaneous onset of labour up to 41 completed weeks beyond this period induction was done by sweeping followed by medical and surgical inductions. Elective Cesarean Section $(\mathrm{C} / \mathrm{S})$ was done in 3 patients $(3 \%)$. Previous study on spontaneous group was $32.5 \%$. Elective CIS was done in previous study group were $6 \%, 4 \%$ \& $1.4 \%$ respectively ${ }^{10,11,12}$. This variation is due to selection criteria which excludes CPD, mal-presentation, pregnancy associated with complications and so on. Foley's catheter was used to induce labour in those cases which had less cervical scoring. Total 19 patients received induction by Foley's catheter but only one case failed. No infection occurred. More promising result was shown by SS Ratnam's series which showed $92 \%$ success rate $^{2}$. In this hospital, over all cesarean rates is $29.75 \%$. So, overall cesarean section rate was much higher in prolonged pregnancy $(40 \%)$ which was due to foetal distress and failed induction. But in other studies rates were $17 \%, 20-25 \%$ and $18 \%$ respectively ${ }^{10,12,13}$.

The foetal well-being was monitored by assessing Foetal Heart Rate (FHR) and colour of the liquor during labour. CTG (Cardiotocography) was used (external) but there was no scope for foetal scalp blood $\mathrm{P}^{\mathrm{H}}$. As there was high false (+)ve result in CTG. So, there might be some error in foetal monitoring clinically. To avoid foetal risk,C/S rate become higher in this study. Foetal outcome was monitored by using APGAR score just 5 minutes after delivery. Foetal outcome with APGAR score was 7 in $86 \%, 11 \%$ having moderate to severe asphyxia, one baby died in early neonatal period. So, total perinatal deaths in this study was 3 , among these, 2 were IUD. This figure was very less in relation to other study $12 \%, 3.6 \%$ respectively ${ }^{9}$. In this study, the maternal morbidity is due to PPH and UTI which constitute $5 \%$ cases. There were no puerperal sepsis or wound infection. Previous study showed $17 \%$ \& $38 \%$ respectively, ${ }^{4,10}$. 
This extremely low rate can be explained by free checkup facilities, free medicine and operation, timely vehicle and other administrative and medical back up supplied by Armed Forces. But this is not the situation in rest of the hospital ${ }^{4,5}$. There was no maternal mortality in this study group. Neonatal morbidity is $30 \%$ in relation to physiological jaundice, umbilical sepsis, and acute RTI. Other study ${ }^{4}$ showed rate was $36 \%$. This similarity was due to overall neonatal care consciousness of mother where are same in all communities including armed forces families. Perinatal mortality and morbidity was increased in postdated pregnancy which could be reduced by timely and judicious induction of labour ${ }^{14,15}$.

There were two IUFD in this series which were due to postmaturity, which were occurred at home as patients came late. Foetal jeopardy with continued intra uterine existence as well as the excellent results of induction of labour justifies the active approach $^{16,17,18}$. Neonatal morbidity in the form of jaundice was $23 \%$ which was more in induction group. Postdated pregnancy increases perinatal mortality, perinatal morbidity and maternal morbidly but it does not increase the maternal mortality, operative delivery due to induction of labour and foetal macrosomia. Foetal macrosomia were three in number which represent $3 \%$ of cases $^{19,20}$. No study was available to compare it.

Routine induction was given in all cases over $41+$ weeks of pregnancy. There was no benefit of induction of labour in foetal macrosomia with unfavourable cervix. So, it again proved some peoples believe that foetal macrosomia and unfavourable cervix increases the cesarean section rate. Previous study series concluded and established that active intervention reduces the rate of cesarean section ${ }^{10,11}$. As the study was done in a referral hospital thus proper selection, adequate care, proper judgment could not always be done in all cases, some patients came with all checkup outside with no or late trimester USG; sometimes even in labour. All these increase the cesarean delivery rate in this series. Better outcome would be expected if proper active interference was done in appropriate case and in optimum time with outmost care.

\section{Conclusion}

Postdated pregnancy is a high risk pregnancy having $50 \%$ risk of recurrence in next pregnancy. It increases the foetal complication in the form of foetal distress, maconium aspiration syndrome, birth trauma etc. It also increases rate of instrumental delivery and operative delivery.

\section{References}

1. Arias F. Practical Guide to High Risk Pregnancy and Delivery. Mosby-year Book 2nd ed, 1993; 150-9.

2. Ratnam, SSK Bhasker Rao, S Arulkumaran. Obstetrics and Gynaecology for Post-Graduates. Orient Lengmen Ltd, India, 1994; Vol 2: 90-5.

3. Alan H Decherney, Lauren Nathan, T Murphy Goodwin, et al. Current Diagnosis and Treatment Obstetrics and Gynecologic. McGraw-Hill Medical Publishing Division., 10th ed, USA, 2007: 187-8, 283-95.

4. Rahim Ayesha. Dissertation on Diagnosis, Management and Outcome of Prolonged Pregnancy. A Study of 50 Cases in Bangobandhu Sheikh Mujib Medical University Hospital in 2000.

5. Afroza Begum. Dissertation on Outcome of Prolonged Pregnancy. A study of 50 Cases in Sylhet MAG Osmani Medical College Hospital in 1999.

6. Luckes M, Buckett W, Altirevic Z. Comparison of Outcomes in Uncomplicated Term and Post-term Pregnancy following Spontaneous Labor. J Perinat Med 1998; 26(6): 475-9.

7. Matijevic R. Outcome of Post-term Pregnancy: a Matched - Pair Case Control Study. Croat Med Journal 1998 Dec; 39(4): 430-4.

8. McMahon MJ, Kuller JA, Jankowistz J. Assessment of Post-term Pregnancy. Am Fam Physician 1996 Aug; 54(2): 631-6.

9. Krusteva M, Malinova M, Milchev N. The use of Prostaglandins in Prolonged Pregnancy and their effect on the new born Infant. Akush Ginekol (Sofina) 2000; 39(2):7-9. 
10. Kaplan B, Goldman GA, Peled Y, et al. The Outcome of Post Term Pregnancy: A Comparative Study. J Perinat Med 1995; 23(3): 183-9.

11. Usher RH, Boyd ME, Maclean FH et al. Assessment of Fetal Risk in Postdated Pregnancies: Am J Obstet and Gynaecol 1988: 158-259.

12. Friesen E. Post-dates Pregnancy Midwifery. Today Int Midwifery 1997; fall (43): 17-867.

13. Weinstein D, Ezra Y, Picard R et al. Expectant Management of Post-term Patients: Observations and Outcome. J Matern Fetal Med 1996 Sep-Oct; 5(5): 293-7.

14. Bresadola M, Lo Mastro F, Arena $V$ et al. Prognostic Value of Biophysical Profile Score in Postdated Pregnancy. Clin- Exp- Obstet- and Gynecol 1995; 22(4): 330-8.

15. DC Datta. Text Book of Obstetrics including Perinatology and Contraception. Kolkata, India, 5th ed, 2002.
16. Rossi EM, Philipson EH, Williams TG, et al. Meconium Aspiration Syndrom; Intrapartum and neonatal Atributes. Am J obstet gynecol 1989; 161: 1106-10.

17. O Relilly Green CP, Divon MY. Predictre Volume of Amniotic Fluid Index for Oligolydramnos in Patient with Prolonged Pregnancy. J Matern fetal Med 1996 Jul-Aug; 5(4): 218-26.

18. Chauhan SP, Suilvian CA, Vittan TC et al. Parous Patient estimate of Birth Weight in Post term Pregnancy. J-perinatal 1995 Ma-J; 15(3):192-4.

19. Peter L Williams, Roger War Wick, Mary Dyson et al. Gray's Anatomy. London (ELBS), 37th ed: 150-6.

20. Charles R, Whit field Dewhurts. Text Book of Obstetrics and Gynaecology for Post Graduates. Blackwell Science Cambridge. London, 6th ed: 1999. 